\title{
Validating Existing ICT Infrastructure of RMG Sector: A Study on Bangladesh
}

\author{
Nymatul Jannat Nipa \\ Department of Management Information Systems, University of Dhaka, Dhaka, Bangladesh
}

Email address:

nipa@du.ac.bd

\section{To cite this article:}

Nymatul Jannat Nipa. Validating Existing ICT Infrastructure of RMG Sector: A Study on Bangladesh. International Journal of Industrial and Manufacturing Systems Engineering. Vol. 5, No. 3, 2020, pp. 28-38. doi: 10.11648/j.ijimse.20200503.11

Received: July 27, 2020; Accepted: August 17, 2020; Published: September 3, 2020

\begin{abstract}
Application of ICT on the structure, assumptions, operation process and decision making in garments industry results in huge benefits. This paper investigates the existing information about the ICT infrastructure of RMG sector of Bangladesh. It broadly encompasses three main objectives. The preliminary objective was to discover the general and advanced ICT applications which are being used currently in RMG sector of Bangladesh. The second objective was to investigate about the existing and probable barriers in using the ICT infrastructure and the third objective of this study was to evaluate the values obtained by using the ICT infrastructure model in RMG sectors of Bangladesh. A robust survey procedure was carried out to extract the information regarding this sector. An ICT infrastructure model is being proposed after analyzing the surveyed information. This paper reveals some crucial information about the three objectives including growing level of emphasis on the use of general and advanced ICT applications in RMG sectors, disclosure of several types of barriers for using the ICT infrastructure. Finally it realized the obtained values by using this infrastructure. This paper elucidates the positive impression for the use of proposed ICT infrastructure and advanced ICT applications.
\end{abstract}

Keywords: Ready Made Garments, ICT, ICT Infrastructure, ICT Applications, Bangladesh

\section{Introduction}

Information and communication technology (ICT) is a very well-known term in the recent perspective. Like a touch stone, it brings about a radical change in the core activities of our personal and professional life. The applications of modern ICT are being used by local industries and companies nowadays. Bangladesh is a south Asian country with large number of populations compared with the other countries belonging to the same economic status. The current economic status of this south Asian country is considered as a developing country which economy is progressing continuously. The current economic state of this developing country will be changed by the near future with the increasing use of ICT in production sector. The continuous improvement of all these sectors and industries are largely dependent on the increasing use of ICT applications which gives them more efficient and potential form of operations. The main focus of this paper is the ICT applications and its infrastructure in RMG sectors of Bangladesh. In the year 1960, Bangladesh has firstly started the realistic use of information technology for the purpose of Nuclear Research. That was the initial stage of the ICT use in Bangladesh. At present, each and every task of an industry is performed with the help of ICT and computer. Nowadays, IT industry has been flourished by the introduction of several IT firms. RMG sectors in Bangladesh are not lagging behind in the use of ICT technology. There are several activities and divisions in the RMG sectors that include ensuring the proper supply of raw materials, efficient operations in production, quality control department, and dealing with native and foreign dealers, payment systems, client satisfactions, and proper management of HRM in the RMG sectors. Information and communication technology has become an integral part of the garments Industry. Employee attendance (clocking in), shipment dispatching, ERP software implementation [1], CAD/CAM system for pattern making or plotting, computerized cutting machine, online FIT approval, ERP for inventory tracking in the production management, mailing solution, preparation of MIS reports, voice chatting, semiautomatic and fully automatic sewing machines and real time communication with buyer through online solutions like 
Skype- all these jobs are done by the use of ICT. RMG sector remarks ICT not as a tool for competitive advantage but a necessary instrument for running day to day business successfully.

As an export-oriented industry, IT industry has turned into an extremely potential sector for the national economy in Bangladesh. Apart from being utilized as an exporting product, IT industry is essential for the increasing uninterrupted performance of other. Nowadays, the applications of IT are considered as a potential tool for retaining the market position in both national market and the global market. Wherever other developing countries fully concentrate on the ICT applications in their business activities, Bangladesh has just started its journey in the path of Information technology.

\section{Methodology of the Study}

\subsection{Research Design}

This research has been conducted to analysis the use of ICT application in the RMG sector and to find out the relevant information regarding the usage of those ICT applications. Present research paper is of descriptive type and based on primary data collected through questionnaire filled by the employees of the garments. The secondary data includes reference books, journal, research papers and internet. Most of theoretical parts of this paper have been collected from several ICT Books and journals

\subsection{Sampling Plan and Procedure}

Sampling Population: the 100 executives of RMG sectors were target population of this study.

Sampling Procedure: Convenience sampling procedure has been followed as the survey participants are the senior level manager and getting their appointment was an arduous task and have to rely on our personal connection. We have used the data collected in questionnaire in computerized tabular form and analyzed those data on Google Form, SPSS software to get the graphs, statistical measures.

\subsection{Data Collection}

Primary Source: Questionnaire and Interview from the selected top-level employees of the RMG sectors

Secondary Data: Secondary Data have been collected from the internets, respective websites of different garments, journals, MIS Books and articles.

Collection Procedure of Data: Personal interview and email on the appointed scheduled time provided by the survey participants

\subsection{Data Analysis}

Collected Data are analyzed through using tables and graphical charts from to analyze them properly. And collected responses were inputted into google form to determine the central tendency, percentage. The data collected from the different sources were analyzed. Statistically weighted scale was used in answering the research questions. The responses of the participants of questionnaire were statistically measured on the scale of Likert:

5. Strongly agree, 4. Agree, 3. Neutral, 2. Disagree, 1. Strongly disagree.

\subsection{Scope and Limitation}

Scope of the study:

This paper is highly concerned with the ICT department of the garment industry. The scope for the study was high as our research population includes many garments of Bangladesh. But due to time limitation and less accessibility to top tire management of those garment, we have to consider it.

Limitations of the study:

1. Less accessibility to confidential data of garment industry

2. Time limitations

3. Restricted connection with the top-level managers of the Garments sector

4. Less information available online

\section{Literature Review}

ICT is a short form which stands for information and communication technology which is a set of technological tools and techniques. These tools and techniques are used to collect, generate, disseminate information among a group of people and set a useful communication with others. Information and communication technology include mobile, telephone, computers, wireless, radios, internet and many other internet technologies. Instant messaging, VOIP, tale conferencing, video conferencing, email service etc. are the advanced applications of ICT [2]

Selwyn (2002) states that information and communication technology is a term which covers a wide range of technological applications, digital broadcast technologies, telecommunication technologies as well as electronic information resources. ICT therefore, encompasses a range of technologies, information and resources.

ICT is the advanced information processing and utilization with the help of digital electronic tools and computers. It covers the several functions like information collecting, processing, storage, retrieval, dissemination of the processed information (College Workouts, 2018). ICT is a combination of tools and technologies which cover the information and communication sectors mainly used in manufacturing and services industries which represent data and information in electronic form [3] Beckinsale and Ram (2006) defined ICT as it is any sorts of technology which is used to gather process and distribute of information and also focuses on the usage of information.

ICT is such a technology which is used by both individuals and organizations for their several purposes including education [4] daily living [5], and social networking [6] and different business-oriented communication like email, video 
conferencing, teleconferencing, cloud computing etc.

RMG stands for ready-made garments which also known as the different textile industries of Bangladesh. It is a very much potential manufacturing industry which has massproduced finished textile products. Different types of fabrics and yarns are used in the production system in this industry. The garment industry can be categorized according to the types of fiber used in the production [7].

ICT and RMG sectors are deeply involved in different foreign countries over the world. Bangladesh is not fully prepared to use the modern ICT applications in the RMG sectors. It is now the initial phase of using ICT applications in this sector. From the procurement of raw materials and other resources this sector has to face several tasks like maintaining supply chain management, communicating with the partners and clients, attracting the native and foreign investors, performing the exporting functions, ensuring the safety and security issues etc. Several ICT applications and frameworks has already invented with a view to make easy of these tasks.

It can ensure the customer satisfactions ICT is highly used in the supply Chain Management in RMG sectors in Bangladesh. It manages the information between business partners and this information is being modified by the corresponding authority which helps in inventory reduction. As the result the productivity also increased.

Moodley (2002) stated that the increasing globalization and upcoming challenge in RMG sectors has reduced the significance of e-business in local apparel sectors. He also observed that there is an essential criterion for achieving the global competitiveness by a firm which is the mutual integration of information and communication systems in the organizational value chain.

Paul (2004) suggested that technology sellers need some laws for the protection of their patent of uniqueness. ICT has a forceful contribution in the path of achieving strong competitive position in the market place and helps to make the operations more sustainable. Not only ICT helps the RMG sectors to increase productivity but also satisfy the customers by their garments products. Product tracking and virtual prototyping are the two powerful ICT based application which are successfully applied in the RMG sectors [8]. By considering the volatile nature of economic, political and environmental situations, ICT applications are highly required by the modern RMG industries in their supply chain management, different safety issues, transportations and business communications. It also brings the competitive advantages for the industry from the global markets [9].

Different sustainable issues such as resources allocations, environmental protection, waste re-cycling, human resource management are the main focuses which are needed to improve by using the ICT applications with a view to make the product more customized and personalized [10].

For the future garment manufacturing purpose, a framework is suggested which known as Extended Smart Sustainable Organization (XSSO). This proposed one is highly networking oriented and integrative framework for the RMG sectors [11]. With the development of the ICT, organizational and knowledge-based networking, collaborative and effective networking competencies contribute to establish and maintain the profitable relationships with the partners and customers (Grant, 1996; Lorenzoni \& Lipparini, 1999).

XSSO is such a framework which is developed by the analysis of different crucial fields like ICT applications, knowledge management, relationship marketing and cluster analysis, supply chain management and innovation management [12]. It is a core framework which implies the visualization and navigation software tools for selecting, designing and operating functionality and sustainability testing configurations [13]. This model set is a combination of three views namely organizational views, processing views and products views.

RMG sectors can enjoy the operational flexibility and interoperating networks which also make them able to be adaptive in using latest manufacturing technology [14]. Functionality, comfort and design are the intensive considerations for the garment industry which can also be achieved by the Implementations of the holistic frameworks. The newly proposed business model will be adapted for the future organizational target.

Product tracking technology is highly useful tool which has vast use in the supply chain management in RMG sectors. As a product tracking tool, RFID is a very popular identification technology (Wang, Tang, Sheng \& Wang, 2006). RFID technology also helps the RMG sectors to easily maintain the inventory and keep a detail record of the finished RMG products. It also helps by minimizing the time and cost by improving the transportation procedures [15].

Zulck, Koruca \& Borkircher (2011) commented that CAD technology is useful for the three-dimensional (3D) body scanners which is mainly used by the manufacturing department in the RMG sectors.

According to Treanor (2011), ICT ensures the overall sustainability in RMG by influencing the volatile customer behavior, increasing their awareness and new mode of communications.

Magnenat-Thalmann \& Apeagyei (2010) observed that by the use of collaborative manner, modern ICT technologies will be used as applications of creating new design of Readymade Garment. He also added that these technologies are also used to evaluate the quality and design through virtual prototyping. He also added that $3 \mathrm{D}$ technology has opened a new door for the RMG sector which follows a comprehensive methodology and is able to minimize the tasks needed huge time in designing.

Virtual prototyping application is also equally crucial for the economic implications that can reduce the unnecessary costs and increase the efficiency. So, it has a major contribution to the customer relationship management (CRM) (Abecassis-Moedas, 2006).

Digital design toolkit like e-configurators and e-fulfillment is used to conduct activities of supply chain. XSSO is a 
holistic decision support system based on the web which applies the visualization can navigation facilities for the purpose of searching, identifying creating design for the latest technologies in the RMG. Moreover, Internet applications and ICT are viewed as the conductive tools for making the RMG sectors more flexible and lucrative.

This literature review mainly covers the global perspective of ICT infrastructure of RMG sectors. Though there are many firms which use modern ICT applications in their business operations in Bangladesh, I did not find any specific article on the ICT infrastructure in RMG sectors in Bangladesh. That's why; I cannot cover the literature review in Bangladeshi viewpoint.

\subsection{Proposed ICT Infrastructure Model for RMG Sectors of Bangladesh}

According to this research study, ICT infrastructure consists of six factors which includes (1) internet applications, (2) Computer software applications, (3) Applications for preparing payroll accounts and financial statement and their transaction, (4) Applications for stock and inventory control, (5) Application for information system links and customer files and (6) Applications of ICT effecting firm performance by reducing material waste and the rate of rejected items.

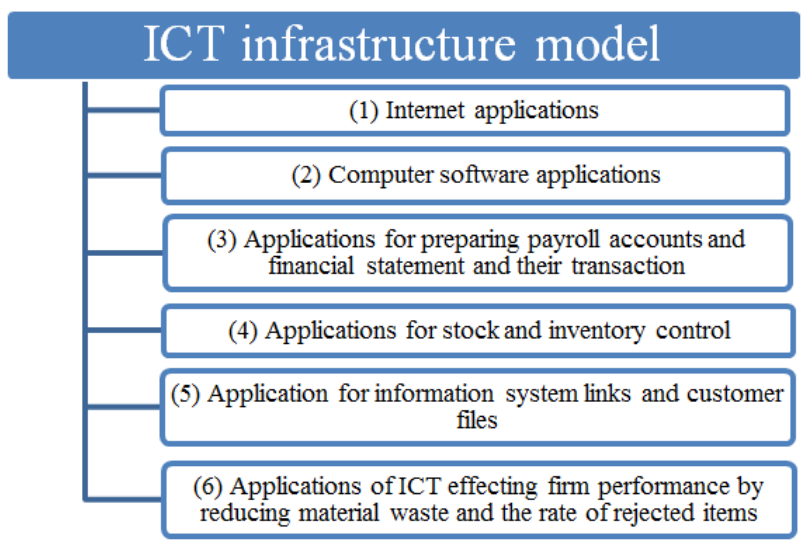

Source: own-design

Figure 1. Proposed ICT infrastructure model.

\subsection{Internet Application}

Internet is the most common and essential element of IT infrastructure model. It is not only used in any particular sector at present but also every sector uses the useful applications of internet. Internet applications are highly used in the communication purposes like email, video conferencing, teleconferencing, instant messaging, Chat rooms, private and group messaging, online discussion forums, Internal blogs, audio and video, Bulk SMS, VOIP, Organizational website etc. most of these internet based communication tools are being used by the RMG sectors with a view to communicate with the suppliers, customers, and stakeholders. These internet applications are also being used within the organizations. Top level management can be connected with the middle and lower level management. Organizational workers belong to a single channel by using the modern internet applications.

\subsubsection{Intranet / Social Intranet}

Intranet is a network system which is mainly used privately in an organization. The main purpose of this network is to share information and other confidential reports among employees. It also strengthens and facilitating group working. Thus, it ensures productivity of all employees of an organization. RMG sector and companies are successfully using Intranets and private networks. Through a research on RMG sector in terms of using Intranet network some benefits, challenges and purpose of using have been gathered and they are:

Purpose of using:

1. To make the repeated tasks more feasible

2. To gather confidential and necessary data in a single database.

3. To collaborate and share information easily.

4. To facilitate internal information of policies, benefits and updates of RMG companies.

Benefits:

1. Developing strong communication network, collaborating and sharing information within RMG companies.

2. Ensuring a flexible corporate culture, reducing operating costs and increasing return on investment, profits.

3. Improving capability to keep employees' records and facilitating customer services.

Challenges:

1. Lack of strong network, IT experts and availability of devices among all employees.

2. Disinterest from employees to engage them in this network of RMG companies.

3. Maintenance and strong security system for reducing hacking is a big issue.

\subsubsection{Chat rooms, Private and Group Messaging}

Chat room is an online platform where users can type a message into a text box, then the message will be almost immediately visible in the group or chat rooms and easily one can read the message. In RMG sector Garments companies are frequently using chat rooms. Employees are using chat rooms for frequently asking questions.

Group messaging is a way where group or mass messaging is done through online platform from any internet-based devices. Group messaging are largely using among employees and customers of RMG companies. It paves the way to increase brand royalty and customer engagement, where customers can discuss and share their opinion, interests, complains. Employee engagement can also be done through group messaging. Necessary information in terms of survey can also be collected via group messaging and instant messaging.

RMG companies can easily develop database for their employees and customers. It helps to get instant notifications, 
easy access to database. It is also cost effective for RMG companies. RMG companies can run open discussion and develop knowledge sharing.

\subsubsection{Discussion Forums}

RMG sectors also used the discussion forums within organization. Discussion forum is an online based site that allows employees to give message and facilitate open group conversation. Employees can easily log in to the site and read message, provide feedback. RMG companies are using discussion forum for sharing and exchanging ideas. Discussion forum mainly helps to gather new ideas, knowledges and facilitate new decisions in terms of new products, new project launching, new plants. All of the employees will be able to share their opinions, ideas and views. Employee engagement can be increased through discussion forum. Workforce can be strengthened through discussion forum.

\subsubsection{Internal Blogs}

An internal blog is also a good ICT application which helps to spread the thought of top management among the workers. As a result, their job responsibility will be improved and job performance will be better. RMG industries usually maintain an internal blog along with its company website.

\subsection{Computer Software Applications}

According to the research work, Computer software applications are mainly used by the production-oriented industries like RMG industries. Because of its easiness and working flexibility, most of the major RMG firms adopt these applications in their production. As a result of their decision, useful results also being realized by them. Some highly used computer software applications are as follows:

Software as a Service (SaaS), Computer Aided Design (CAD), Computer Aided Manufacturing Systems (CAMS) etc.

\subsubsection{Computer Aided Designing (CAD)}

CAD stands for Computer Aided Design. In RMG sector $\mathrm{CAD}$ is using for spreading process, cutting process, sewing processes. Cutting and designing function can smoothly run through CAD. Nowadays fashion designer in RMG companies can handle critical designing and clothing designing in a smooth way. CAD is also known as CADD (Computer Aided Design and Drafting). In RMG sector CAD is suing for clipping of certain parts, adding new shapes, reducing color, resizing etc.

CAD enables to create two- or three-dimensional (2D or 3D) graphical representations of physical objects in terms of clothing design. CAD software is largely using in RMG companies like Garber, Golden Leaser, Lecpayrtra, Fibersim, NX etc. Customers' ideas and interests are using and implementing through CAD software.

\subsubsection{CAMS-Computer aided Manufacturing System}

CAMS is especially designed for the textile and apparel industry. The system has been proven in all areas of the textile supply chain and is now being implemented also in other industries.

There are also some things which have contribution to increase the productivity by CAMS are given below:

Real time production progress reporting

Automatic machine stop detection

Event based or continuous data recording

Recording of operator and shift productivity

PLC connection for online data collection

Scanner and RFID support

Machine monitoring and status supervision

Shift/Operator summary report.

\subsection{Applications for Preparing Payroll Accounts and Financial Statement and Their Transaction}

HRIS means Human Resource Information System. This is mainly used by HR department of an organization and it's a new dimension in HR field. It is kept for collecting and storing data on of organization's employees. HRIS has software packages to run functions like recruitment, learning and development, performance management etc. RMG companies are using HRIS for maintaining employees record keeping, leave and absence management, payroll, compliance, compensation management, career development planning. HR department also uses for training, administrative works, employees' self-service. Software like ATS (Applicant Tracking System) keeps all the records for recruiting candidates. Succession planning under HRIS is using for keeping talent inventory.

Benefits:

1. Improving performance management of employees, efficiency of employees,

2. Helping to budget control and maintain KPI (Key Performance Indicator).

3. Implementing HR strategies, developing decision making and quality of workforce.

So, RMG companies should install new and highly performed HRIS software to improve business activities.

\subsection{Applications for Stock and Inventory Control}

Inventory package is an inventory control system which keeps records the actual amount of inventory needed by the firms and ensures its supply as per it needed. As a result, organization can properly maintain the inventory system within it.

Supply chain management (SCM) means the management of supply chain activities to maximize customer value. It helps to get a sustainable competitive advantage. Mainly business has a chain among all parties like producers, wholesalers, retailers and customers. SCM can ensure a proper flow of raw materials, production, logistics, products and finished goods, information, finances in the most efficiently way. In RMG sector there are two levels of SCM (Macro and Micro level). Macro level deals with Buyers, Brands, Suppliers, and Manufacturers. On the other hand, Micro level deals with services where the RMG companies deal with the buyer, suppler and also deal with negotiation, documentation, communication etc. SCM software like 
planning applications ensure how to fill an order properly and in the best way. Execution applications help to keep the record on current amount of materials, finished goods among all parties. RMG sector of Bangladesh should develop and maintain strong supply chain management.

ERP stands for Enterprise Resource Planning. ERP software keeps the automated process of keeping a manufacturing line which is supplying with materials to meet incoming orders. ERP applications are highly using in finance, manufacturing, human resources and other functions of an organization which will automate back-office business administration functions of that organization. There are some functions of ERP like sales, inventory management, procuring, production and costing of productions.

\subsection{Application for Information System Links and Customer Files}

RMG sector of Bangladesh also concerned about how to maintain the information system links and customer files. With a view to managing these items, some types of applications have been developed. These applications include cloud computing.

Cloud computing is well known application at the present time. It has already used by many different types of firms and industries. It is a system where user firms don't need any physical storage device to store data about customers. It provides the opportunity to store essential data about the organizations and can be retrieved these as per needs. As a result, the storage location will not be unutilized and it also minimizes the organizational cost. As it is an internet-based application, organizational officials can use the stored information anywhere and anytime with internet connection [16].

Electronic Data Interchange shortly known as EDI [17] [18] which is the computer-to-computer exchange of business documents in a standard electronic format between business partners.

\subsection{Applications of ICT Effecting Firm Performance by Reducing Material Waste and the Rate of Rejected Items}

Computer Aided Textile Supervision (CATS) is a software solution used for minimizing inspection costs, while enhancing the production value. Looking at the textile production cycle, mills are continuously improving the efficiency of weaving cloth, thanks to organization and loom technology improvements. On the other hand, the output of the looms must always be controlled, to ensure the required fabric quality and to identify production problems. Inspection, being labor intensive, is costly and often its effectiveness needs to be improved. Some objectives being as follows:

a) Improve inspectors' productivity and efficiency

b) Optimize the value of the produced fabric

c) Report timely information on faults in production

The CATS workstations, installed at each inspection or cutting table, are PCs, stand-alone or connected in a network, with an encoder to measure fabric length and fault locations. Hence CATS enhance production values by which a specific dynamic function optimizes the cutting of the roll, with the goal of providing maximum first quality production, according to the customer's policy. The CATS optimization module has proven to be a well-designed algorithm [19].

\section{Data Analysis and Findings}

\subsection{ICT Applications Used as ICT Infrastructure in RMG}

ICT infrastructure is a framework which encompasses all the devices, networks, protocols and procedures that are employed in the telecoms or information technology fields to foster interaction amongst different stakeholders (Anon, 2018).

With a view to gather knowledge about the current ICT infrastructure of RMG sectors in Bangladesh, an internal survey has been conducted. The intention of this survey is to view the most common used ICT tools in RMG sectors in Bangladesh and proposed an ICT infrastructure model for RMG sector in Bangladesh. The usage of ICT tools can be classified into three main categories. These three categories are 1) General ICT technology usage 2) Production-oriented ICT technology usage and 3) Advanced ICT technology usage [20].

Hypothesis 1: "Most RMG industries use general ICT applications and few use advanced applications"

Table 1. ICT applications used by RMG sectors in Bangladesh.

\begin{tabular}{|c|c|c|c|}
\hline Categories of applications & Total Respondents & Individual ratings & Percentage (\%) \\
\hline \multicolumn{4}{|l|}{ General ICT Applications } \\
\hline Internet access & 100 & 86 & $86 \%$ \\
\hline Email & 100 & 91 & $91 \%$ \\
\hline Bulk SMS & 100 & 82 & $82 \%$ \\
\hline VOIP & 100 & 53 & $53 \%$ \\
\hline Organizational website & 100 & 83 & $83 \%$ \\
\hline Average use of General ICT applications & & & $79 \%$ \\
\hline \multicolumn{4}{|l|}{ Production-oriented ICT applications } \\
\hline Accounting packages & 100 & 33 & $33 \%$ \\
\hline Inventory packages & 100 & 42 & $42 \%$ \\
\hline Human resource packages & 100 & 40 & $40 \%$ \\
\hline Enterprise resource planning (ERP) systems & 100 & 65 & $65 \%$ \\
\hline Customer relationship management applications (CRM) & 100 & 54 & $54 \%$ \\
\hline Supply chain Management (SMC) System & 100 & 69 & $69 \%$ \\
\hline
\end{tabular}




\begin{tabular}{|c|c|c|c|}
\hline Categories of applications & Total Respondents & Individual ratings & Percentage (\%) \\
\hline $\begin{array}{l}\text { Average use of Production-oriented ICT applications } \\
\text { Advanced ICT applications }\end{array}$ & & & $50.5 \%$ \\
\hline Software as a Service (SaaS) & 100 & 28 & $28 \%$ \\
\hline Cloud computing & 100 & 35 & $35 \%$ \\
\hline Content management system (CMS) & 100 & 23 & $23 \%$ \\
\hline Mobile CRM & 100 & 21 & $21 \%$ \\
\hline Mobile payment system & 100 & 45 & $45 \%$ \\
\hline $\begin{array}{l}\text { System visualization. } \\
\text { Average use of Advanced ICT applications }\end{array}$ & 100 & 30 & $\begin{array}{l}30 \% \\
30.33 \%\end{array}$ \\
\hline
\end{tabular}

\section{1) General ICT technology usage}

General ICT technology usage is the core type of ICT applications which are used in RMG sectors very frequently. The general use ICTs consisted of the following technologies:
a) Internet access
b) Email
c) Bulk SMS
d) VOIP
e) Organizational website and
f) Intranet [21].
2) Production-oriented ICT technology usage

As the RMG sector is a production-oriented sector, Production-oriented ICT technology ant are highly used in this sector. ICT technologies have a large contribution on the production related activities in RMG sectors. The most commonly ICT technologies are given below:

a) Accounting packages

b) Inventory packages c) Human resource packages

d) Enterprise resource planning (ERP) systems

e) Customer relationship management applications (CRM) and

f) Supply chain Management (SMC) System

3) Advanced ICT technology usage

The third category of ICT applications used in RMG sector in Bangladesh is known as advanced ICT technology. This type of ICT application tools has very little usage in Bangladesh because its complex infrastructure. This type of ICT applications require advanced technical knowledge to operate. Some advanced ICT applications are given below:

a) Software as a Service (SaaS)

b) Cloud computing

c) Content management system (CMS)

d) Mobile CRM

e) Mobile payment system and

f) System visualization.

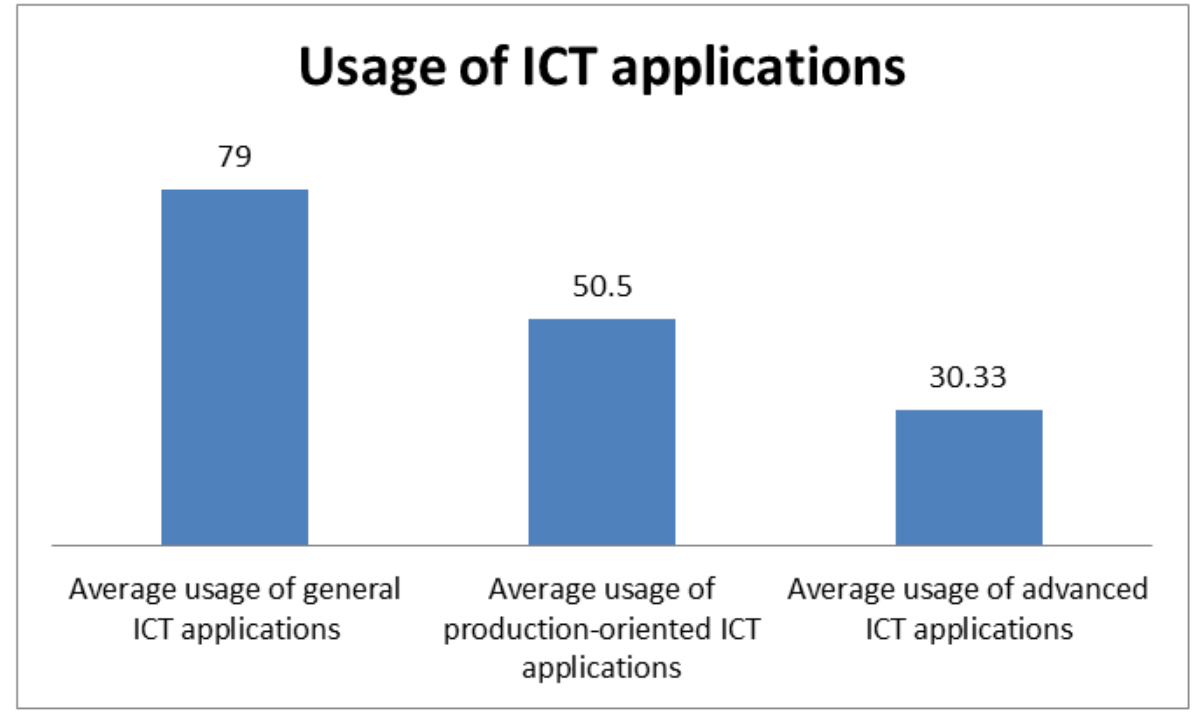

Source: Own design

Figure 2. Average usage of ICT applications.

The above table (table 1) shows that the extent of ICT applications used by Bangladeshi RMG sectors is mainly depends on the general ICT applications. The usage rate of general ICT applications is the highest at 79 percent. Comparing with the other two categories of ICT applications, it has achieved the title to highly used by the RMG industries in Bangladesh. So it is clearly understood that the RMG industries of Bangladesh has already started the use of general ICT applications.

At the same time, it can be seen that the productionoriented ICT applications has achieved the second highest position in the usage of ICT applications. Its score is 50.5 percent. By seeing this survey result, it has a clear understanding that the production-oriented industries like RMG industries have not initiated the heavy use of ICT application in their operations. 
At the third stage of this survey result, it can be seen that the usage rate of advanced ICT application is very poor. This rate is only 30.33 percent which states that the RMG industries of Bangladesh do not take these modern ICT applications cordially. There are some obvious reasons behind this like the ignorance and lack of IT skills. So the RMG officials always try to avoid the latest applications of ICT. As a result, they did not get the increasing facilities from the advanced technology. There are some organizations, who have already initiated the advanced use of some ICT applications to perform their organizational tasks. But their number is relatively very few. So, it can be stated that the first hypothesis becomes true.

\subsection{Barriers of the Current ICT Infrastructure in RMG Industries}

The second question is about the nature of the barriers faced by RMG industries to adopt the ICT infrastructure. It can be clarified that this paper will show the barrier to adopt ICT infrastructure in this section. A set of questionnaires has been made to justify the rate of barrier about the different issues to adopt the ICT applications. There has a hypothesis under this questionnaire which will be known as hypothesis 2.

Hypothesis 2: "RMG industries face very critical barrier when using ICT"

Questionnaire of this section are as follows:

Table 2. Perceived barriers to adopt ICT.

\begin{tabular}{|c|c|c|c|c|c|c|}
\hline $\begin{array}{l}\text { Perceived Barrier }(\mathrm{SD}=\text { Strongly Disagree; } \mathrm{D}=\text { Disagree; } \mathrm{N}=\text { Neutral; } \mathrm{A}=\text { Agree; } \\
\mathrm{SA}=\text { Strongly Agree) }\end{array}$ & SD & D & $\mathbf{N}$ & $\mathbf{A}$ & SA & Weighted Average \\
\hline Employee IT skill level is too low & 2 & 7 & 21 & 38 & 32 & 3.91 \\
\hline Lack of awareness about the benefits of ICT & 3 & 8 & 18 & 45 & 26 & 3.83 \\
\hline Employees satisfaction with traditional technologies & 10 & 22 & 37 & 24 & 7 & 2.96 \\
\hline Security Concerns & 4 & 8 & 18 & 39 & 31 & 3.85 \\
\hline Usage of ICT is too much expensive & 4 & 8 & 22 & 36 & 30 & 3.80 \\
\hline Time constraints & 10 & 20 & 30 & 24 & 16 & 3.16 \\
\hline Business partners, suppliers and customers do not make use of ICT & 5 & 31 & 34 & 21 & 9 & 2.98 \\
\hline Resistance to change within our organizations & 6 & 18 & 15 & 42 & 19 & 3.50 \\
\hline ICT implementation would not deliver the immediate return on investment (ROI) & 3 & 9 & 20 & 35 & 33 & 3.86 \\
\hline No access to ICT infrastructure & 12 & 25 & 39 & 17 & 7 & 2.82 \\
\hline Low level of existing hardware technology in place & 11 & 14 & 34 & 19 & 22 & 3.27 \\
\hline No sources of reliable and vendor-independent information & 18 & 27 & 25 & 23 & 7 & 2.74 \\
\hline
\end{tabular}

The second components of the research investigated into the nature of barriers regard to ICT adoption and used by the RMG sectors of Bangladesh. The hypothesis of this research is that:

A weighted average mean score has been calculated for all of the perceived barriers to the use of ICT which is shown in the above table. The weighted average mean score was calculated by giving the value and acronyms are SD $($ Strongly Disagree $)=1 ; \mathrm{D}($ Disagree $)=2 ; \mathrm{N}($ Neutral $)=3 ; \mathrm{A}$ $($ Agree $)=4$; and SA $($ Strongly Agree $)=5$.

From the above table it can be seen that the most critical perceived barriers were "Employee IT skill level is too low", "ICT implementation would not deliver the immediate return on investment (ROI)", "Security Concerns", "Lack of awareness about the benefits of ICT" and "Usage of ICT is too much expensive". They have considered as more critical because their weighted average value is relatively higher than others. The weighted average score of these four questionnaires are 3.91, 3.86, 3.85, 3.83 and 3.80 respectively. On the other hand, the relatively least critical barriers were "No sources of reliable and vendor-independent information", "No access to ICT infrastructure", "Employees satisfaction with traditional technologies" and "Business partners, suppliers and customers do not make use of ICT". Because their weighted average score is comparatively low. Their weighted average values are 2.74 for "No sources of reliable and vendor-independent information", 2.82 for "No access to ICT infrastructure", 2.96 for "Employees satisfaction with traditional technologies" and 2.98 for "Business partners, suppliers and customers do not make use of ICT". All of these weighted average scores are below 3.00.

At the same time, it should be noticed that there are some questionnaires which have moderate weighted average scores. Their weighted averages scores belong to the range 3.00 to 3.50 are considered under this moderate group. The weighted averages values with Questionnaires under the moderate groups are 3.50 for "Resistance to change within our organizations", 3.27 for "Low level of existing hardware technology in place" and 3.16 for "Time constraints". From the above finding, it is clear that Bangladeshi RMG sectors experienced a lot of critical barriers to ICT adoptions and use.

Hence RMG industries believe that the modern ICT applications are too much expensive to buy and cost more than the value they might add. At the same time, it is realized by conducting the survey that employee's satisfaction with traditional technologies is a moderate barrier for the new ICT infrastructure. Sometimes the workers feel comfortable to perform their activities by using traditional technology instead of modern technology. Lack of proper knowledge and training on the new technology, they think so.

"Business partners, suppliers and customers do not make use of ICT" is a less crucial barrier because almost all of the industries use ICT in their business communication. So, the numbers of business partners, customers and suppliers are 
very few who do not use ICT.

\subsection{The Obtained Value from Current ICT Infrastructure in RMG Sectors}

RMG sectors can obtained a lot of benefits with the help of new ICT infrastructure in this sector. Several modern ICT applications and tools can make the task easy and quick which may generate more profits from the business. An efficient ICT infrastructure may also add value in every single step in the RMG sectors like maintaining reliable and long-term communication with the native and foreign customer. Not only that, it can help the industry officials to establish a one-to-one communication with their suppliers of raw materials. Quick decision making are needed sometimes among the business people staying at different location but they can be connect through several ICT applications like teleconferencing, videoconferencing, instant messaging etc. Modern ICT infrastructure has also contribution to the improvement of product quality and product design. Computer aided design shortly known as CAD which is considered as very helpful to upgrade the product design. ICT infrastructure can increase the profit margin in RMG industry of Bangladesh by improving the communication, production activities as well as export of these RMG products. The given questionnaires have been used to conduct the survey about the value-added role of ICT infrastructure in RMG sectors of Bangladesh.

Hypothesis 3: "Obtained ICT add value to the RMG industries"

The below table shown the perceived value added by the ICT adoption. The core perceived values are Clients satisfaction, Improvement of product quality, Turnaround time, production efficiency, industry become marketable, effectiveness of the industry, achieved target, efficient scheduling, better condition of the stock level, relationship, workers' morality, increase revenue, decreased operational costs etc.
We have again used the five-level Likert scale to analysis the questionnaires that how much ICT added value to the RMG industries.

According to the responses from different organizations, the most crucial value added factors are "Relationships with suppliers have been improved", "Operational costs have decreased since the ICT has been adopted", "Stock levels are always up to date", "Industry has become more effective since the adoption of ICT infrastructure", "Short term target are more achievable", "Scheduling has become more efficient", "Production are more efficient", "Organizational goals are being met with more ease", "Product quality has been improved", "Improvement of product quality by using ICT", "Industry has become more marketable" and "Clients satisfaction has increased". These are considered as important because their weighted average value is relatively higher than the same value of other questionnaires. It can be seen that weighted average value of individual questionnaire are 4.36 for "Relationships with suppliers have been improved", 3.89 for "Operational costs have decreased since the ICT has been adopted", 3.87 for "Stock levels are always up to date", 3.85 for "Industry has become more effective since the adoption of ICT infrastructure", 3.84 for "Short term target are more achievable", 3.83 for "Scheduling has become more efficient", 3.81 for "Production are more efficient", 3.77 for "Organizational goals are being met with more ease", 3.76 for "Product quality has been improved", 3.73 for "Improvement of product quality by using ICT", 3.72 for "Industry has become more marketable" and 3.71 for "Clients satisfaction has increased"

Relationship with suppliers has been improved because of the use of modern ICT applications which have reduced the information gaps between them and contribute to improve the strong relationships. Industries can properly arrange the work schedules and ensure the proper utilization of resources which also contribute to minimize the operational costs.

Table 3. Perceived value through the adoption of ICT.

\begin{tabular}{|c|c|c|c|c|c|c|}
\hline $\begin{array}{l}\text { Value Added (SD= Strongly Disagree; } D=\text { Disagree; } N=\text { Neutral; } A=\text { Agree; } \\
\text { SA=Strongly Agree) }\end{array}$ & SD & D & $\mathbf{N}$ & $\mathbf{A}$ & SA & $\begin{array}{l}\text { Weighted } \\
\text { Average }\end{array}$ \\
\hline Clients satisfaction has increased & 6 & 12 & 21 & 27 & 34 & 3.71 \\
\hline Improvement of product quality by using ICT & 2 & 15 & 20 & 34 & 29 & 3.73 \\
\hline Turnaround time has improved & 7 & 12 & 32 & 27 & 22 & 3.45 \\
\hline Production are more efficient & 1 & 7 & 27 & 40 & 25 & 3.81 \\
\hline Industry has become more marketable & 4 & 11 & 22 & 35 & 28 & 3.72 \\
\hline Industry has become more effective since the adoption of ICT infrastructure & 3 & 9 & 20 & 36 & 32 & 3.85 \\
\hline Short term target are more achievable & 3 & 9 & 21 & 35 & 32 & 3.84 \\
\hline Scheduling has become more efficient & 4 & 11 & 14 & 40 & 31 & 3.83 \\
\hline Stock levels are always up to date & 3 & 11 & 15 & 38 & 33 & 3.87 \\
\hline Organization has become more profitable & 6 & 16 & 28 & 30 & 20 & 3.42 \\
\hline Organizational goals are being met with more ease & 3 & 11 & 20 & 38 & 28 & 3.77 \\
\hline Employees are able to work from remote locations & 20 & 22 & 28 & 19 & 11 & 2.79 \\
\hline Staff morale has increased & 3 & 18 & 20 & 34 & 25 & 3.60 \\
\hline Relationships with suppliers have been improved & 1 & 3 & 5 & 41 & 50 & 4.36 \\
\hline Customer base has increased & 4 & 16 & 23 & 27 & 30 & 3.63 \\
\hline Increase revenue since implementation & 6 & 12 & 47 & 23 & 12 & 3.23 \\
\hline Operational costs have decreased since the ICT has been adopted & 5 & 13 & 10 & 32 & 40 & 3.89 \\
\hline
\end{tabular}


According to the above table, some others relatively less important value-added factors are "Employees are able to work from remote locations", "Increase revenue since implementation", "Organization has become more profitable", "Turnaround time has improved", "Staff morale has increased", "Customer base has increased" etc.

These are less important value-added factors because ICT applications cannot provide direct benefits to the industries but it can create a workable environment which can help to increase revenue. So, it is a supportive tool to increase revenue. It has very little contribution to increase staff's morale. RMG sectors are a production-oriented industry, so the workers cannot make useful contribution from the remote location. It can possible to communicate among stakeholders from remote areas. Lastly, efficiency in production is not considered as crucial value-added factors because the employees are not skilled to work with the help of modern ICT applications. So, they cannot always conduct efficient production.

It is important to realize that none of any individual question carries zero weighted average values. So, it is clear that all of these factors add incremental value which can be more or less based on the different situations. So, the hypothesis 3 which has stated that "Obtained ICT add value to the RMG industries" becomes true.

\section{Recommendation}

After conducting a survey and completing this paper, there are some limitations and bad sides of the ICT infrastructure has been appeared. Now, it is time to provide some recommendations with a view to overcoming these limitations. Some such possible recommendations are given below:

a) Analyzing the current technological environment and ICT infrastructure very carefully

b) Measuring the adaptability of the ICT applications according to the industry requirements

c) Improving the IT skills of the employees by offering the training facilities

d) Improving the security system of the ICT infrastructure

e) Making the ICT infrastructure more flexible and easier to use

f) Introducing a common way of communication inside and outside of the organizations through modern ICT applications

g) Improving the reliability and timeliness of the infrastructure

h) Viewing the ICT infrastructure as important to maintain the quality

i) Different quality control applications have to introduce for revising the product quality

All of these elements are essential parts of an ICT infrastructure. The infrastructure will be applicable only when different applications will be considered as useful for each other and works as a unit. At last of the discussion, it can be recommended that the six applications are the core element of the proposed ICT infrastructure model for RMG sector in Bangladesh.

\section{Conclusion}

This paper mainly looked at the ICT infrastructure which will be proposed for the RMG sectors in Bangladesh. It has already discussed a lot about the different available ICT infrastructure, applications, tools and technologies. At the same time, there have some limitations to implement the modern ICT infrastructure. Before the proposal of an ICT infrastructure, we have considered the capacity and the probable limitations. In the question of capacity, there are some considering issues like internet accessibility, geographical locations, technical expertise etc. in the term of limitations, we have to consider the technical knowledge of the workers, capital inadequacy, poor organizational infrastructure, lack of modern devices, ignorance of modern applications, tendency to being unchanged, insecurity etc. all of these are the considering factors for proposing the ICT infrastructure for RMG sector of Bangladesh. ICT infrastructure covers all of the applications used in information sectors and communication sectors. Like all other industries, RMG industries are largely depend on the advanced use of ICT applications. Infrastructure of ICT can be varied by industry to industry but the main components will remain the same at every time. Communication Technology as a "Global Market Maker" Communication technology also serves as a "Market maker". Given the intense economic competition among nations, missed opportunities due to lack of communications access will have more dire consequences in the future. To be successful, Bangladesh as a developing country must be prepared to compete in a global economy in which production takes place around the world on a decentralized and flexible basis. For example, a small business that serves a single niche market in a developing country can increase its size by using communication technologies like the internet to identify similar niche markets in other countries. This means that if developing countries deploy advanced communication technologies in tandem with developed countries, they can also compete in the expanding global services market on a more equal basis. Deployment of a better communication system encourages catalytic social, economic and political interaction, which in turn stimulates further network development and deployment. Specific examples for Bangladesh include the Ready-Made-Garments (RMG) industry as well as potential data-entry and other software related industries.

\section{References}

[1] Candra, S. (2011). The Road of ERP Success: A Framework Model for Successful ERP Implementation. Binus Business Review, 2 (2), p. 1118. 
[2] Techterms.com. (2018). ICT (Information and Communication Technologies) Definition. [online] Available at: https://techterms.com/definition/ict [Accessed 27 Jan. 2018].

[3] Michalsons. (2018). What is ICT? What is the Meaning or Definition of ICT? [online] Available at: https://www.michalsons.com/blog/what-is-ict/2525 [Accessed 29 Jan. 2018].

[4] Richardson, H. J. (2009). A 'smart house' is not a home: The domestication of ICTs. Information Systems Frontiers, 11 (5), 599-608.

[5] Busetti E., Dettori, G. Forcheri, P., and Ierardi, M. G. (2007). A pedagogical approach to the design of learning objects for complex domains. Journal of Distance Education Technologies, 5 (2), 1-17.

[6] Rose, M. (2007). The transmission of culture in a globalized world: The challenge of new technologies. Canadian Issues, Winter 2007, 55-57.

[7] Tis-gdv.de. (2018). Ready-made garments. [online] Available at: http://www.tisgdv.de/tis_e/ware/textil/konfektion/konfektion.htm\#informati onen [Accessed 30 Jan. 2018].

[8] Cepolina S., Scarsi R. (2011), Apparel supply chain management: ICT contribution to networking sustainability and competitiveness, in Bartolo H. et al. Proceedings of SIM 2011 Sustainable Intelligent Manufacturing, IST Press Lisbona.

[9] Daiser R. (2009). Designing the Smart Organization: how breakthrough corporate learning initiatives, drive strategic change and innovation. San Francisco: Jossey Bass /Wiley Press.

[10] Binder M., Janicke M., Petschow U. (2001). Green industrial restructuring: international case studies and theoretical interpretations. New York: Springer Verlag Press.

[11] Abernathy, F. H., Volpe A. \& Weil D. (2006). The future of the apparel and textile industries: prospects and choices for public and private actors. Environment and Planning, 38 (12), 2207-32.

[12] Cepolina S. (2011), Extended Smart Sustainable Organization in Garment industry, in Lather, Saini, Khatri, Strategies and innovations for sustainable organizations, McMillan publisher India Ltd.

[13] Vieira V. A. (2009). An extended theoretical model of fashion clothing involvement. Journal of Fashion Marketing Management, 13 (2), 179-200.

[14] Mo J. P. T., Nemes L. (2001). Global engineering, manufacturing and enterprise networks. Dordrecht: Kluwer Academic Publishing.

[15] Porter M. E. (2001). Competition in global industries. Harvard: HBS Press Book.

[16] Sill, A. (2015). Emerging Standards and Organizational Patterns in Cloud Computing. IEEE Cloud Computing, 2 (4), pp. $72-76$.

[17] EDI Basics. (2018). What is EDI (Electronic Data Interchange)? | EDI Basics. [online] Available at: https://www.edibasics.com/what-is-edi/ [Accessed 14 Feb. 2018].

[18] Hartley, J. (1993). Electronic data interchange. Economist Intelligence Unit.

[19] Zhong, P., Ye, T., Shi, Y. and Tu, X. (2012). Research on computer-aided analysis and reverse reconstruction for the weave pattern of fabric. Textile Research Journal, 83 (3), pp. 298-310.

[20] KumarNayak, M. and Sanghamitra Mohanty, D. (2012). Schedule Risk Analysis of ICT Infrastructure Projects. International Journal of Computer Applications, 38 (5), pp. 15.

[21] Maldeni, H. and Jayasena, S. (2009). Information and Communication Technology Usage and Bank Branch Performance. International Journal on Advances in ICT for Emerging Regions. 